УдК 316.346.32-053.9

\title{
ОТНОШЕНИЕ К СТАРОСТИ КАК ФАКТОР БЛАГОПОЛУЧНОГО СТАРЕНИЯ
}

\author{
Аникина Екатерина Алексеевна1, \\ anikinaea@tpu.ru \\ Иванкина Любовь Ивановна 1 , \\ ivankina@tpu.ru
}

${ }^{1}$ Национальный исследовательский Томский политехнический университет, Россия, 634050, г. Томск, пр. Ленина, 30.

\begin{abstract}
Аникина Екатерина Алексеевна, кандидат экономических наук, доцент Школы инженерного предпринимательства Национального исследовательского Томского политехнического университета.

Иванкина Любовь Ивановна, доктор философских наук, профессор Отделения социальногуманитарных наук Школы базовой инженерной подготовки Национального исследовательского Томского политехнического университета.
\end{abstract}

Актуальность исследования обусловлена влиянием ценностей, разделяемых обществом, на формирующееся отношение и действия к людям другого исторического поколения, что особенно актуально при развитии современных процессов интенсивных и быстрых трансформаций норм, стандартов, ценностей в обществе с эффектом временного дисхроноза - сосуществованием в одно время и в одном пространстве людей, живущих в разных темпомирах. Цель: выявить изменения в представлениях современного общества о ценности старости; рассмотреть, как меняется представление о возможностях и потенциале данного периода жизни человека в современном обществе, реализующем ключевую стратегию в отношении старости (активное старение в обществе всех возрастов); обосновать, что доминирующее отношение к старости, фиксируемое в конкретных проявлениях, от общественного мнения и социальных стереотипов до принимаемых политических решений, выступает фактором повышения удовлетворенности жизнью в целом. Методы: исторический и феноменологический подходы, позволившие рассмотреть благополучное старение во взаимосвязи с идеями относительно старости. Результат исследования: проанализированы теоретические конструкты представлений о старости и старении человека, показано, что образ старости закрепляет в общественном сознании стереотипы социальных ожиданий, имеющих предписывающий характер при выборе действий пожилым человеком.

Ключевые слова: Благополучие, благополучное старение, активное старение, ценностный подход к старости, адаптационно-регуляторная модель старения.

\section{Введение}

Актуальность обращения к исследованию проблем старения с позиций ценностного подхода обусловлена тем, что в пожилом возрасте окружающий мир воспринимается через призму эмоционально значимых социальных отношений. То, как в социуме относятся к старению и старости, является для пожилого человека важным фактором оценивания степени удовлетворенности жизнью, выступающей основным индикатором субъективного благополучия [1].

Исходя из того, что возраст аккумулирует в себе позитивные и негативные аспекты, которые служат основанием для закрепления множества стереотипов, пожилой воз- 
раст имеет свой арсенал подобных предубеждений, связанных в первую очередь с представлением о старости как времени дожития, упадка сил, увядания, уныния, неполноценности, потерь.

Старение человека, как и любой другой период его жизненного цикла, представляет собой комплексный процесс, включающий все жизненно важные уровни - физический, физиологический, социальный, экономический, психологический, духовный. Сквозь возраст рефреном проходит ключевая предрасположенность и ценность возраста на определенном жизненном цикле человека.

Являясь сложным, комплексным феноменом единства объективного и субъективного параметров жизни конкретного человека, благополучие с помощью механизма доминирующих идей, ценностей регулируется социальными ожиданиями и отношением к определенным социальным явлениям, в том числе к проблеме старения человека. Ценности и мотивы определяют индивидуальные рамки восприятия значимого для человека. Именно ценностно-мотивационный фактор задает такую характеристику благополучия, как широту, к которой можно отнести то, что является для индивида значимым.

Поскольку старение сопровождается снижением жизненной активности человека и происходящими переменами в его жизни, постольку отношение со стороны других начинает играть роль регулятора выбора действий в этом возрасте. В отношении к старению и старости на предыдущих этапах развития человечества четко проявились и реализовывались в разных социокультурных системах два подхода. В основе одного доминировало уважение к старости, помощь и поддержка, другой подход отрицал ценность старости и признавал справедливым социальное презрение к старикам. Несмотря на их существенную разницу, данные подходы рассматривают проблемы старения преимущественно как проблемы дефицитов, нехватки, и как следствие, необходимости компенсации, помощи, защиты, поддержки, что фиксирует старость как отягощенное бремя для общества.

Современный этап развития в отношении проблем старения характеризуется формированием новой мировоззренческой парадигмы, ориентированной на либерализацию старения, в которой отражается понимание возраста в единстве конструктивных и деструктивных аспектов данного жизненного цикла человека [2]. Разработанный в 2002 г. Всемирной организацией здравоохранения подход «активного старения» направлен на улучшение качества жизни в пожилом возрасте, он нацелен на расширение возможностей для поддержания и сохранения здоровья, обеспечения социальной защищенности и оптимизации участия в жизни общества [3].

Ключевая дихотомия восприятия и формирования положения людей старшего возраста, заключающаяся, с одной стороны, в практиках избегания старения, или либерализации от старения, а с другой - в поиске внутренних ресурсов самого процесса старения, или либерализации старения, была обоснована в книге «Old age» (2003) J. Vincent. J. Vincent определяет старший возраст как период неограниченных возможностей, основным барьером для реализации которых выступают «укорененные в обществе стереотипы, а не естественные и неизбежные признаки старшего возраста» [4, с. 61].

На сегодняшний день мировое сообщество рассматривает пожилых людей в качестве позитивного фактора в процессе социального развития. Перспективной является идея пересмотра формулы «детство-учеба, взрослость-работа, старость-покой», когда все три вида деятельности (учеба, работа, отдых) должны быть обеспечены в любом трудоспособном и активном возрасте. Смене приоритетов в подходах к проблеме старения способствовало внимание мирового сообщества в лице Всемирной ассамблеи 
ООН. Проблеме успешного старения в феврале 2015 г. был посвящен номер журнала «The Gerontologist» [5].

Широкое распространение в последнее время получили понятия «благополучное старение», «активное долголетие». Благополучное старение определяется как предпочтительный для человека исход, «при котором он способен адаптироваться и справляться с нарастающими возрастными изменениями, сохраняя при этом цель и смысл жизни» [6-7]. Активное старение означает прежде всего то, что пожилые люди находятся в хорошем состоянии здоровья, они активно вовлекаются в профессиональную деятельность, являются полноправными членами общества, чувствуя себя более независимыми в повседневной жизни и более активно выполняют свои социальные роли [8]. Под «активным долголетием» понимают путь к самосовершенствованию через постоянную постановку себе физических и умственных задач человеком [9].

Какие идеи предшествовали новому подходу и в чем заключаются качественные изменения в понимании?

\section{Идеи, формирующие модель поведения в отношении людей старшего возраста}

Один из ответов на поставленные вопросы был дан профессором 3. Айтнером, ведущим геронтологом Германии, проводившим исследование с целью выявления образа старости, передаваемого посредством изображения, объектом которого стали детские книжки. Оказалось, что из одной книги в другую используются одни и те же образы стариков, отражающие тяжесть прожитых лет, скорбь и отрешенность от окружающего миpa [10, с. 16]. Данный эксперимент позволил подтвердить гипотезу о том, что социальные ожидания посредством доминирующих идей, образов, представлений, ценностей формируют стереотипы, влияющие на восприятие людей данной возрастной группы.

Акцентированию внимания на ограниченных возможностях стареющих людей способствовало доминирование в подходах к старости и старению идеи трех строго последовательных стадий жизни, известных как разделение жизни на три части - обучение, работа, отдых. Третья стадия жизни описывалась как стадия зависимости, упадка, потерь и была обоснована в модели неполноценности.

В 90-е годы 20-го столетия изменения на рынке труда стали следствием того, что условная концепция течения жизни, которая представляла финальную фазу жизни как отдых, сменилась концепцией «активного старения». Отличительная особенность новой концепции является ее направленность на поощрение длительного, продолжающегося участия пожилых людей в общественной жизни. Акценты внимания были смещены на то, какими знаниями и компетенциями они обладают, а не на том, что люди не могут делать. В конце 90-х годов Всемирной организацией здравоохранения было принято решение реализовать данную концепцию в социальных программах, что способствовало быстрому внедрению идей в исследовательскую и практическую деятельность [11].

Впервые в научный оборот понятие «благополучное старение», под которым понималась удовлетворенность человека прожитой и настоящей жизнью, было введено в 1961 г. Р. Хевигхерстом. Данное понятие фиксировало теоретически обоснованную и экспериментально выявленную положительную взаимосвязь между активным образом жизни в пожилом возрасте и удовлетворенностью жизнью. Еще ранее в исследованиях Э. Эриксона была обоснована концепция психосоциального развития индивида (1950), согласно которой каждый человек проходит в своем развитии восемь этапов жизненного цикла и последний этап решает специфическую эволюционную задачу - переосмысление прожитого и осознание факта старения. Итогом благоприятного прохождения этапа становится идея ценности жизни, конструктивная оценка достигнутого и способ- 
ность оставаться продуктивным, для неблагоприятного исхода характерна безнадежность, оценка прожитого как бессмысленного и не имеющего ценности.

В ходе предпринятых дальнейших исследований Р. Хевигхерст с коллегами пришли к выводу о том, что по своим психологическим и социальным качествам пожилые люди ничем не отличаются от людей среднего возраста. Авторы определили несколько компонентов для измерения удовлетворенности жизнью у человека в старшем возрасте:

- позитивная оценка себя и своей занятости;

- образ жизни, социально приемлемый для данной возрастной группы;

- субъективное ощущение счастья и удовлетворенности собственной жизнью;

- активность на уровне среднего возраста.

В конце 80-х годов XX века наравне с концепцией «благополучного старения» получила популярность концепция «успешного старения». Дж. Роуи и Р. Канн в 1987 г. опубликовали результаты исследований, в которых была сформулирована и обоснована концепция «успешного старения». В соответствии с данной концепцией на успешное старение влияют три фактора: высокий уровень умственной и физической деятельности, общее физическое здоровье, продуктивное социальное взаимодействие [12]. Дж. Ивамаса и М. Ивасаки в 2011 г. предложили модель успешного старения, которая включает в себя физическое, психологическое, функциональное и социальное здоровье. На текущий момент времени к данным компонентам добавлены материальный и духовный аспекты жизни, что позволяет с полным основанием рассматривать модель успешного (благополучного) старения как многогранную модель.

Согласно адаптационно-регуляторной теории старения (автор В.В. Фролькис) в старости одновременно с процессами возрастной деструкции и дезорганизации происходит развитие и укрепление адаптационно-регулятивных процессов, направленных на выживание, повышение жизнеспособности, увеличение продолжительности жизни [13]. Адаптация означает способы регулирования, приспособления, гармонизации взаимодействия личности со средой. Человек выступает активным субъектом, который приспосабливается к среде в соответствии со своими интересами, потребностями, стремлениями и активно самоопределяется, закрепляясь в решении. На этом уровне индивид представлен как набор функций, среди которых восприятие ситуации и принятие решений, способность к переменам в ситуации, информативность процессов.

Обоснованная в 60-70-х гг. ХХ в. В.В. Фролькисом концепция процесса антистарения, получившего название «витаукт», который, наряду с процессом старения, возник в ходе эволюции, легла в основу нового подхода к старости как периоду продолжающейся, а не завершающейся стадии развития [14]. При этом роль самого человека в регулировании данных процессов по сравнению с предыдущими этапами жизненного цикла резко возрастает, поскольку от его активного отношения к своей жизни, к себе, к предпринимаемым действиям в регулировании развития своего организма и индивидуальности зависит развитие процесса старения. Каждый человек является, как утверждал А. Маслоу, своим собственным проектом и создает себя сам [15]. Это во многом объясняет природу экзистенциально значимого для пожилого человека факта принятия своего жизненного опыта, достижений в контексте взаимообусловленности эвдемонистического, связанного с ощущением осмысленности и целесообразности жизни, и аффективного, связанного с эмоциональными состояниями и чувствами, аспектов благополучной жизни.

Объяснение факту одинаково значимого влияния на человека объективных и субъективных факторов для его активного долголетия и благополучного старения находим в теории психологических систем, автором которой является В.Е. Клочко [16]. 
Исходя из принципа системной детерминации, многомерный мир человека может быть представлен как целостная психологическая система в единстве с объективным миром в своей продленности в те сферы, которые имеют смысл, значение, ценность для самого человека. Системный комплекс представляет собой определенное множество разнокачественных систем (объектов), взаимодействующих между собой с целью формирования определенного единства как внутреннего, субъективного отношения человека к действительности, образующего феномен собственной жизни.

В структуре эмоциональных переживаний в пожилом возрасте имеет значение оценка достигнутого и наличие перспектив, устремленности в конструктивное будущее. Чтобы выявить взаимосвязь влияния мироощущения на оценку уровня благополучия, в 2017 г. было проведено социологическое исследование, в котором приняли участие мужчины и женщины, проживающие в городах и сельской местности Томской области, старше 50 лет. Выборочная совокупность опрашиваемых составила 400 чел.

В ходе исследования была выявлена позитивная жизненная позиция у большинства респондентов. Результаты проведенного опроса показали, что своей жизнью полностью удовлетворены $27 \%$ и 56,8\% - скорее удовлетворены; полностью не удовлетворены $2,3 \%$ и скорее не удовлетворены - 9,8\%; 4,3\% респондентов затруднились оценить удовлетворенность своей жизнью. Более $70 \%$ респондентов принимают жизнь такой, какая она есть, и берут от жизни лучшее. Данная адаптационная стратегия подтверждает хорошую адаптируемость пожилых людей к жизни в обществе.

Важным показателем благополучного старения является факт отсутствия культурной изолированности в восприятии происходящего в жизни пожилого человека. В проведенном нами опросе на это указывает то, что большинство респондентов имеют позитивную оценку ценности того, что ими делается в жизни. На вопрос «Чувствуете ли Вы себя выброшенными из жизни?» только 1,0 \% респондентов ответили «да, чувствую» и $8,0 \%$ респондентов сомневаются в выборе ответа, но склоняются больше к тому, что чувствуют себя выброшенными из жизни. $91 \%$ респондентов отметили, что они живут полноценной жизнью.

В группе пожилых людей, воспринимающих будущее негативно, уныние на момент опроса испытывали $63,2 \%$ респондентов, в том числе постоянно испытывали уныние $15,8 \%$ респондентов. $89 \%$ респондентов отметили, что у них есть время делать то, от чего они действительно получают удовольствие, $11 \%$ респондентов так не считают. Все респонденты, имеющие такое мнение, представлены возрастной группой от 71 года и старше, имеющие доход ниже 6 тысяч рублей в месяц.

В группе респондентов, принимавших участие в исследовании, среди оптимистично настроенных респондентов в 1,7 раза больше тех, кто оценивает свое здоровье как хорошее или очень хорошее. И наоборот, в группе отчаявшихся, пессимистично настроенных в 7,5 раз больше респондентов оценивают свое здоровье как плохое.

Полученные результаты в ходе проведенного нами опроса совпадают с результатами, полученными ранее другими исследователями. Согласно исследованиям Л.Л. Карстенсен и соавторов, старость характеризуется существенным улучшением в регуляции эмоций, увеличением удовлетворенности межличностными отношениями и сохранением психологического благополучия [17-20].

Исходя из ценностного подхода к проблеме старения человека, можно сделать вывод о том, что мировоззренческие и ценностные ориентиры непосредственным образом влияют степень удовлетворенности жизнью и то, как будет проходить этот процесс, напрямую зависит от того, как общество воспринимает этот период жизни человека. 


\section{Заключение}

Общественная потребность в новой мировоззренческой парадигме и ценностных ориентирах возникает в том случае, если прежняя ценностная ориентация не отвечает требованиям изменившейся исторической и общественной действительности. Новые мировоззренческие установки относительно старения меняют приоритеты в отношении к старости как периоду дожития и формируют посредством изменившегося восприятия конструктивные, оптимистичные основания для активной продолжающейся, а не затухающей, жизни. Ведущая ценностная ориентация в отношении к старости, выступающая альтернативой прежней, изменяет взгляды, представления и мотивацию людей в этот период жизни.

В целом реализация современного ценностного подхода к проблеме старения как продолжающейся жизни, актуализируя идею позитивной старости, оказывает непосредственное влияние на повышение благополучия через предлагаемые образцы старения и старости, следуя которым пожилой человек осуществляет выбор действий, ориентированных на благополучное старение, и как следствие, обусловливающих повышение степени удовлетворенности жизнью.

Исследование выполнено при финансовой поддержке РФФИ в рамках научно-исследовательского проекта «Разработка комплексной оценки эффективности вовлеченности пожилых людей в региональный социум», проект №19-010-00984.

\section{СПИСОК ЛИТЕРАТУРЫ}

1. Совместное совещание экспертов по целевым ориентирам и индикаторам здоровья и благополучия для политики Здоровье-2020. URL: http://www.euro.who.int/_data/assets/pdf_file/0005/197312/ e96819r.pdf (дата обращения 14.09.2018).

2. Стюарт-Гамильтон Я. Психология старения. - СПб.: Питер, 2002. - 256 с.

3. Концепция успешного старения. URL: http://www.vechnayamolodost.ru/articles/teorii-stareniya/ koncuspsta61 (дата обращения 10.09.2018).

4. Рогозин Д.М. Пять книг о либерализации старения // Психология зрелости и старения. - 2012. № 4. - C. 59-66. URL: http://www.sociologos.ru/novosti/Obzor_sociologicheskoj_literatury_ot_Dmitriya_ Rogozina (дата обращения 10.09. 2018).

5. Грин О. Старость во благо. URL: https://rusplt.ru/health/starost-vo-blago-15762.html (дата обращения 30.08. 2018).

6. Involving Older Age: the route to twenty-first century well-being: Final Report / M. Hoban, V. James, P. Beresford, J. Fleming. - Cardiff, 2013. URL: http://www.royalvoluntaryservice.org.uk/Uploads/ Documents/SoA_Closingprojectreport_final_web_v2.pdf (дата обращения: 04.12.2018).

7. Максимова С.Г. Старость: социальное отчуждение или социальное принятие // Социология и политология. - 2007. - № 4. - С. 179-194.

8. This Site European Year for Active Ageing and Solidarity between Generations 2012. URL: http://europa.eu/ey2012/ey2012main.jsp?catId=971\&langдId=en (дата обращения: 10.08.2018).

9. Стрельникова И.В. Социально-психологические аспекты активной старости. URL: http://docme.ru/doc/49207/strel._nikova-stat._уа (дата обращения: 06.02. 2019).

10. Активное старение: от концепции к реальности / сост. И.И. Кекух, Н.И. Кекух. - Гомель: Барк, 2013. $-28 \mathrm{c}$.

11. Альмуканов К.Г. Благополучное старение: ретроспективный анализ и современное состояние // Фундаментальные исследования. - 2014. - № 8-1. - С. 212-216. URL: http://fundamentalresearch.ru/ru/article/view?id=34537 (дата обращения 03.02.2019).

12. Старость во благо - новость из рубрики «Здоровье, актуальная информация, обсуждение, новости, дискуссии на Newsland». URL: http://hw.net.ua/starost-vo-blago-novost-iz-rybriki-zdorove-aktyalnaiainformaciia-obsyjdenie-novosti-diskyssii-na-newsland (дата обращения 03.02.2019).

13. Фролькис В.В., Мурадян Х.К. Экспериментальные пути продления жизни. - Л.: Наука, 1988. - 248 с.

14. Фролькис В.В. Старение и увеличение продолжительности жизни. - Л.: Наука, 1988. - 239 с.

15. Маслоу А. Психология бытия. - М.: Рефл-бук; Киев: Ваклер, 1997. - 304 с. 
16. Клочко В.Е. Постнеклассическая наука и проблема объяснения в психологии // Методология и история психологии. - 2008. - № 1. - С. 165-178.

17. Carstensen L.L., Charles S.T. Emotions in the second half of life // Current Directions in Psychological Science. - 1998. - № 7. - P. 144-149.

18. Emotion experience in everyday life across the adult life span / L.L. Carstensen, M. Pasupathi, U. Mayr, J. Nesselroade // Journal of Personality and Social Psychology. - 2000. - № 79. - P. 644-655.

19. Rosow I. Socialisation to Old Age. - Berkeley: University of California Press, 1974. - 188 p.

20. Краснова О.В., Лидерс А.Г. Социальная психология старения. - М.: Академия, 2008. - 288 с.

Поступила 03.04.2019 2. 
UDC 316.346.32-053.9

\title{
ATTITUDE TOWARD AGE AS A FACTOR OF SAFE AGEING PROCESS
}

\author{
Ekaterina A. Anikina1, \\ anikinaea@tpu.ru \\ Lubov I. Ivankina ${ }^{1}$ \\ ivankina@tpu.ru \\ 1National Research Tomsk Polytechnic University, \\ 30, Lenin Avenue, Tomsk, Russia
}

Ekaterina A. Anikina, Cand. Sc., associate professor, National Research Tomsk Polytechnic University.

Lubov I. Ivankina, Dr. Sc., professor, National Research Tomsk Polytechnic University.

The relevance of this work is stipulated by the social values divided into the attitude and actions forming in relation to people of the past generation. This becomes more important due to the rapid development of the up-to-date rules and standards with the effect of the time-zone disease, i. e. a coexistence of people living in different tempoworlds. The aim of this work is to determine the changes in the ideas about safe ageing in the modern society. The paper considers how the modern society which implements the key value and the strategy of age - active ageing of all ages, changes the idea about the opportunities in this period of life. It is shown that the attitude to age observed in specific aspects ranging from the social opinion and social stereotypes to policy decision-making tends to dominate the life satisfaction as a whole. This study utilizes the historical and phenomenological approaches to the phenomenon of safe ageing allowing us to detect its relationship with the ideas of the ageing process. Research findings include the analysis of the theoretical constructs of the ideas about age and ageing. It is found that the age character forms an idea in public consciousness about social expectations being more prescriptive in selecting actions by elderly persons.

Key words: Welfare, safe ageing, active ageing, value-based approach, adaptive regulatory model of ageing.

The research was financially supported by the RFBR within the research project «Development of comprehensive assessment of the efficiency of senior citizens involvement in regional community», project no. 19-010-00984.

\section{REFERENCES}

1. Sovmestnoe soveshchanie ekspertov po tselevym orientiram i indikatoram zdoroviya i blagopoluchiya dlya politiki Zdorove-2020 [Joint Meeting of Experts on targets and health and well-being indicators for the Health-2020 policy]. Available at: http://www.euro.who.int/_data/assets/pdf_file/0005/197312/e96819r.pdf (accessed 14 September 2018).

2. Styuart-Gamilton Ya. Psikhologiya stareniya [Psychology of aging]. St. Petersburg, Piter Publ., 2002. $256 \mathrm{p}$.

3. Kontseptsiya uspeshnogo stareniya [The concept of successful aging]. Available at: http://www. vechnayamolodost.ru/articles/teorii-stareniya/koncuspsta61 (accessed 10 September 2018).

4. Rogozin D.M. Five Books on the Liberalization of Aging. Psychology of maturity and aging, 2012, no. 4, pp. 59-66. In Rus. Available at: http://www.sociologos.ru/novosti/Obzor_sociologicheskoj_literatury_ot_ Dmitriya_Rogozina (accessed 10 September 2018).

5. Grin O. Starost vo blago [Old age is the benefit]. Available at: https://rusplt.ru/health/starost-vo-blago15762.html (accessed 30 August 2018). 
6. Hoban M., James V., Beresford P., Fleming J. Involving Older Age: the route to twenty-first century wellbeing: Final Report. Royal Voluntary Service. Electronic data. Cardiff, 2013. Available at: http://www.royalvoluntaryservice.org.uk/Uploads/Documents/SoA_Closingprojectreport_final_web_v2.pdf (accessed 04 December 2018).

7. Maksimova S.G. Old age: social exclusion or social acceptance. Sociology and political science, 2007 , no. 4, pp. 179-194. In Rus.

8. This Site European Year for Active Ageing and Solidarity between Generations 2012. Available at: http://europa.eu/ey2012/ey2012main.jsp?catId=971\&langдId=en) (accessed 10 August 2018).

9. Strelnikova I.V. Sotsialno-psikhologicheskie aspekty aktivnoy starosti [Social and psychological aspects of active aging]. Available at: http://docme.ru/doc/49207/strel._nikova-stat._ya (accessed 6 February 2019).

10. Aktivnoe starenie: ot kontseptsii k realnosti [Active aging: from concept to reality]. Compilers I.I. Kekukh, N.I. Kekukh. Gomel, Bark Publ., 2013. 28 p.

11. Almukanov K.G. Successful aging: a retrospective analysis and current status. Basic research, 2014, no. 8-1, pp. 212-216. In Rus. Available at: http://fundamental-research.ru/ru/article/view?id=34537 (accessed 3 February 2019).

12. Starost vo blago - novost iz rubriki «Zdorove, aktualnaya informatsiya, obsuzhdenie, novosti, diskussii na Newsland» [Old age good - News from the «Health, relevant information, news, discussions on Newsland»]. Available at: http:/hw.net.ua/starost-vo-blago-novost-iz-rybriki-zdorove-aktyalnaiainformaciia-obsyjdenie-novosti-diskyssii-na-newsland/ (accessed 3 February 2019).

13. Frolkis V.V., Muradyan Kh.K. Eksperimentalnye puti prodleniya zhizni [Experimental ways to prolong life]. Leningrad, Nauka Publ., 1988. 248 p.

14. Frolkis V.V. Starenie i uvelichenie prodolzhitelnosti zhizni [Aging and increased life expectancy]. Leningrad, Nauka Publ., 1988. 239 p.

15. Maslou A. Psikhologiya bytiya [Psychology of being]. Moscow, Relf-buk Publ.; Kiev, Vakler Publ., 1997. $304 \mathrm{p}$.

16. Klochko V.E. Post-non-classical science and the problem of explanation in psychology. Methodology and history of psychology, 2008, no. 1, pp.165-178. In Rus.

17. Carstensen L.L., Charles S.T. Emotions in the second half of life. Current Directions in Psychological Science, 1998, no. 7, pp. 144-149.

18. Carstensen L.L., Pasupathi M., Mayr U., Nesselroade J. Emotion experience in everyday life across the adult life span. Journal of Personality and Social Psychology, 2000, no. 79, pp. 644-655.

19. Rosow I. Socialisation to Old Age. Berkeley, University of California Press, 1974. 188 p.

20. Krasnova O.V., Liders A.G. Sotsialnaya psikhologiya stareniya [Social psychology of aging]. Moscow, Akademiya Publ., 2008. 288 p.

Received: 3 April 2019. 